\title{
Reflections on Including Disability in Social Protection Programmes
}

\author{
Marguerite Schneider, Wamundila Waliuya, Joseph Munsanje and \\ Leslie Swartz
}

\begin{abstract}
This article presents reflections on including disability in social protection and, specifically, in social assistance programmes. The main considerations for including disability in such programmes are: (a) the factors associated with disability that create vulnerabilities for people with disabilities and their household (e.g. social exclusion, the need for care and extra costs); (b) the nature of disability targeting within social protection and social assistance programmes; and (c) the measurement of disability - a complex but key factor in ensuring accurate targeting and monitoring of impact. This article describes these considerations in relation to experiences in three African countries - Uganda, Zambia and South Africa - and concludes with recommendations on recognition of disability as a vulnerability factor, and how targeting and measurement can and should be addressed for inclusion of disability in social assistance programmes.
\end{abstract}

\section{Introduction}

There is growing awareness of the importance of including disability in social protection

programmes and, specifically, in targeting beneficiaries of social assistance grants. ${ }^{1}$

Disability is a contributor to poverty, and poverty contributes to creating or aggravating disability (Braithwaite and Mont 2008; Yeo and Moore 2003; Elwan 1999). Disability is thus an important vulnerability factor that can lead people with disabilities and their households to resort to strategies that push them into severe or critical poverty (e.g. selling household assets to pay for assistive devices, or leaving paid employment to take care of a disabled household member). It is therefore crucial for disability to be factored into social protection and social assistance programming, to ensure that such damaging 'coping' strategies are not required.

The inclusion of disability in such programmes requires consideration of three important aspects: (a) factors associated with disability that create vulnerabilities for the disabled person and their household (e.g. social exclusion, need for care and extra costs); (b) the implicit or explicit nature of disability targeting, and (c) the assessment of disability. The aim of this article is to critically review and reflect on how these three aspects are addressed in the social assistance programmes currently implemented in low- and middle-income countries.

\subsection{Definition of disability}

The UN Convention on the Rights of Persons with Disabilities (CRPD) describes people with disabilities as including 'those who have longterm physical, mental, intellectual or sensory impairments which in interaction with various barriers may hinder their full and effective participation in society on an equal basis with others' (United Nations 2006: Article 1).

Disability is complex and multidimensional. Disability is the consequence of living with a health condition. ${ }^{2}$ Key to understanding disability is recognising the impact of environments in which impairments occur some environments are more disabling than others. This applies both to the physical environment (it is easier for example for wheelchair users to access buildings which have ramps and lifts) and to the social environment (e.g. people with cerebral palsy may struggle to access reproductive health care if health care providers see them as asexual beings). Marginalisation and social exclusion remain strong features of the experiences of people with 
disabilities: 'it is discrimination, rather than disability itself, which is at the heart of the exclusion experienced by disabled people thereby leading to a greater risk of poverty' (LwangaNtale 2003).

People with disabilities experience many of the same problems related to poverty as do their peers from the same communities, but these problems may be compounded by disability. A person with a disability who cannot pay for wheelchair repairs may also not be able to access health care or go to buy food. Social isolation associated with disability reduces the possibilities of support and access to opportunities. If policymakers do not recognise the crucial role of external barriers (both physical and attitudinal) in determining disability, they may focus interventions on the individual alone, thereby missing the opportunity to make social or environmental changes that will not affect the impairment itself but may dramatically enhance social and economic participation. A simple intervention like Brailling documents, for example, may allow blind people to work where they could not work before.

\subsection{Disability and chronic illness}

Chronic illness is commonly confused with disability. Chronic illness is a health condition that may, but not necessarily, lead to disability. If a chronic illness is diagnosed and effective treatment is initiated, the person should be able to function fully. However, chronic illness is a vulnerability factor in itself, as there are costs involved in managing the illness (e.g. ongoing access to health care including transport). Poor households struggle to meet these costs and are easily pushed into severe poverty (Goudge $e$ al. 2009a,b). The consequences of poor management can lead to disability.

Thus chronic illness and disability are both important vulnerability factors. However, the management of each differs. The aim of providing social assistance for chronic illness, for example, is to maintain the person's functioning, which is done through ensuring equitable access to health care and good nutrition. Disability, on the other hand, is about limitations in functioning which require much more than health care in order to ensure that people with disabilities are able to access opportunities that are available to others.

\subsection{Impact of social assistance for people with disabilities and their households}

Studies undertaken in Zambia and South Africa show clear benefits from cash transfers (Tembo and Freeland 2007; MCDSS and GTZ 2007; Goudge et al. 2009b; de Koker et al. 2006). Children are healthier and show better school attendance, instances of begging are reduced and use of health care services increases for beneficiary households. These benefits are similar for households with and without people with disabilities.

Looking specifically at beneficiary households with a person with a disability in Zambia (Schneider et al. 2011), the primary benefits reported are sustainability at a basic level and providing an element of control for this person. Families are enabled to pay for support when required and acquire control of this support; that is, they can request it when required rather than having to wait for a volunteer to be willing or able to assist. These benefits in turn lead to improved health status, access to investment opportunities, increased sense of worth as a person, and greater participation in community activities. Some respondents described how they are now able to attend church as they can pay their dues, become members of cooperatives and take part in voting for committees.

Most of the people with disabilities in beneficiary households were household heads. Although this trend has not been confirmed by more extensive quantitative data analyses (data are not available), it may be that disability has the strongest effects when the person with the disability is the household head.

A South African study on coping strategies of households where members have a chronic illness, showed that combined access to cash transfers (including but not limited to disability benefits) plus access to free health care services provided the best context for coping by households. Those households with only one of these two components of social protection struggled and often fell into critical poverty (Goudge et al. 2009a).

\section{Three country social assistance programmes}

Our reflections draw on work undertaken in three countries that address disability within specific social assistance programmes, namely: 
(1) the social cash transfer (SGT) scheme in Zambia; (2) the Social Assistance Grants for Empowerment (SAGE) programme in Uganda; and (3) social assistance grants for disability in South Africa (Disability Grant (DG) for adults and Care Dependency Grant (CDG) for children). The first author was involved in the work in all three countries.

\subsection{Zambia's social cash transfer (SCT) scheme}

In Zambia, Sightsavers undertook a qualitative study in two districts (Kalomo and Monze) to obtain evidence on the impact of social cash transfers on households with a disabled member as well as on the disabled individual. Such information is generally lacking in the social protection literature (Marriott and Gooding 2007). This study involved semi-structured interviews primarily with heads of beneficiary households with and without a disabled member, and heads of non-beneficiary households with a disabled member. Focus groups were run with Community Welfare Assistance Committee members (CWAGs).

The social cash transfer in Zambia is a household grant and the amounts transferred are in the region of US $\$ 15$ per month, paid bi-monthly. The main criteria for eligibility are described by Schubert and Goldberg (2004):

1 Critically poor or destitute households experiencing chronic hunger and undernutrition, who are begging and are in danger of starvation;

2 Incapacitated households where breadwinners are sick or have died; or where there are no able-bodied persons of working age. The dependency ratio is understood to be high in these households.

These criteria suggest that people who are disabled are seen as incapacitated. This is, however, a limited view of disability that focuses on the individual without understanding the role of contextual factors in determining inclusion in education, work and society generally. The Zambian programme does not specifically assess disability or ill-health in targeting beneficiary households. However, evaluations of the programme show that both these factors are present in a number of households (Tembo and Freeland 2007). Unfortunately, the data collected do not record disability or illness status systematically, making it difficult to analyse outcomes by these characteristics.

Community Welfare Assistant Committees (CWACs), who are responsible for doing the targeting of beneficiary households, are aware of the importance of looking at disability and chronic illness. They commented that, while disability and illness are important, they do not assess these characteristics specifically and, furthermore, that having disability in a household does not necessarily mean that the household is critically poor. They reported being able to assess the impact of disability and chronic illness easily, as they know community members personally and can observe their functioning on an ongoing basis. This nuanced understanding suggests that community-based targeting may be more effective than a simplistic administrative classification which assigns all disabled or chronically ill people as automatically eligible for social assistance. On the other hand, this approach is unlikely to be feasible when the social cash transfer scales-up to national level, as community-based targeting is very costly and time-consuming, and relies on personal knowledge.

\subsection{Uganda's Social Assistance Grants for Empowerment (SAGE)}

SAGE is being initiated during 2011 and will pay eligible individuals and households around US $\$ 10$ per month. SAGE has two sub-components: an Old Age Grant for people over 65 and a Vulnerable Families Support Grant (VFSG), which targets households with limited labour capacity. Eligibility for VFSG is assessed according to simple vulnerability indicators, including older people, children, orphans and people with moderate or severe disabilities. A composite score is calculated according to household composition, and the highest scoring 15 per cent of households are enrolled in the VFSG.

Disability is one of a number of elements included in the household assessment, the assumption being that disability leads to incapacitation, as in the Zambia SCT programme. The inclusion of disability as a criterion for eligibility necessitated devising simple but accurate tools for assessing disability in very young children ( $0-5$ years) and among older children and adults. A pilot testing exercise was undertaken that involved applying the tools 
in two rural villages in Uganda and analysing the results to determine whether the tools were performing adequately. The findings described below come from this pilot study.

\subsection{South Africa's Disability Grant (DG) and Care Dependency Grant (CDG)}

Historically, South Africa has had a welldeveloped social assistance programme, including an Old Age Grant; a Disability Grant for adults; a Care Dependency Grant for carers of disabled children; a Foster Care Grant and a Child Support Grant. These grants are all individually targeted with eligibility criteria such as a means test, age thresholds and, for the Disability Grant and Care Dependency Grant, moderate to severe disability and a need for extra care (in the case of children). The amounts paid are large relative to payment levels in other countries and to wages paid for casual and informal work in South Africa. The current (2011) amounts paid for the DG, CDG and Old Age Grant are around US\$154 per month to individual beneficiaries.

The South African work was carried out over a number of years and included reviewing the current procedures for assessing disability, developing new assessment tools for the Disability Grant and Care Dependency Grant and developing policy proposals for social security for chronic illness. The tools were piloted and training of social assistance officials was undertaken.

\section{Inclusion of disability in social cash transfers in three countries}

This section addresses the three concerns raised at the start of this article for the three country programmes.

\subsection{Disability factors creating vulnerabilities}

The Zambian case study suggests that there are three main factors arising from disability that make individuals and their households vulnerable to poverty:

- Additional costs related to buying assistive devices, and paying for services such as transport (e.g. double fares for wheelchair and/or attendant), additional care and assistance, and medication. Paying someone to do everyday tasks, such as fetching water or wood, ploughing the fields or cooking meals are costs associated with being disabled.
- Additional care needs such as are required by a child with severe disability, or adults who are unable to care for themselves. This need is met through paying someone or by a household member leaving paid employment to do the caring.

- Loss of social networks that would facilitate access to support and livelihood opportunities.

While these factors have been noted in all three countries, the Zambian study was the only one that collected this information specifically. Disabled non-beneficiaries of social cash transfers described being isolated and struggling to access health care or getting the assistance they require. Parents or carers of disabled children commented on the high costs associated with accessing appropriate educational facilities for these children, often far away from home. A number of interviewees described the loss of livelihood opportunities associated with the onset of disability, for example, when a disabled person requires full-time care. Respondents pointed towards the support that social assistance can provide in gaining access to services or social activities. Disabled beneficiaries described taking part in church activities, or being part of agricultural cooperatives, now that they could pay their dues.

\subsection{Targeting disability in social assistance programmes}

Current social assistance approaches use either implicit disability targeting criteria (e.g. expecting people with disabilities to be in the poorest households but not assessing disability formally, as in Zambia) or explicit disability targeting criteria (e.g. assessing disability and allocating an associated weighting to a household, as in Uganda, or targeting grants specifically for people with disabilities, as in South Africa). One reason for this distinction is that the programmes in Zambia and Uganda target household poverty, while the South African programmes target individual disability and therefore require a more detailed assessment of disability.

Nonetheless, the Zambian experience suggests that, while the SCT is inclusive of people with disabilities, it could benefit from making this inclusion explicit, especially when the programme scales-up and community-based targeting that relies on personalised knowledge is no longer feasible. This would necessitate the development 
of a simple standard measurement tool for identifying disability, a strategy for facilitating the inclusion of people with disabilities, and ongoing monitoring and evaluating of the impact of social cash transfers on their households.

The South African experience provides a good example of what can happen when a specifically targeted, means tested and relatively high cash benefit is provided in a context of widespread poverty and unemployment, coupled with a flawed and largely invalid assessment of disability. (Its strong medical focus requires a careful and detailed assessment by skilled trained people, which are in short supply in South Africa and even more so in low-income countries). Targeting becomes confused, resulting in a loss of differentiation between disability and chronic illness. In the context of a high number of chronically ill people living in poverty, and as the main source of benefit for the poor population aged 18-60 years, the Disability Grant has become a de facto chronic illness or poverty benefit (CASE 2005; Schneider and Goudge 2007).

\subsection{Measurement of disability}

The measurement of disability for purposes of determining eligibility for social assistance is not straightforward or standardised. Methods range from quick and simple identification of the presence of a disability (usually moderate to severe in nature) through to complex assessment of a person's functional status.

The three country programmes have quite different approaches to disability identification. The Zambia SCT scheme has no specific or standard identification process or tool and no formal recording of any information on disability. The recognition of disability as an important vulnerability factor was, however, clearly apparent. The current approach to identifying disability in the SCT scheme is problematic in that: (a) it identifies primarily those conditions that are visible and misses out those that may be less visible (e.g. severe depression) and (b) it is timeconsuming as a method to be applied in potentially scaling-up the scheme to national level.

The SAGE assessment in Uganda uses the Washington Group on Disability Statistics' Short Set (WG SS) of six questions. ${ }^{4}$ These ask about difficulties people have in seeing; hearing; walking and climbing stairs; remembering and concentrating; self-care and communication. These questions move away from the traditional approach to measuring disability, which tends to focus on types of disability, such 'deaf, blind, crippled or mentally retarded'. These questions provide a more inclusive and transparent measure of disability, which gives both a profile of functioning and a more nuanced picture of the degree of severity (Schneider 2009; Schneider et al. 2009). For instance, these measures can identify older people as having difficulties which a question on 'disability' would not, as older people do not necessarily see themselves as disabled.

Experience by the Ugandan Bureau of Statistics (UBOS) found the WG SS to be a good measure for identifying disability in the population aged six years and older, but not for the younger population. ${ }^{5}$ This necessitated the development of a separate tool for children aged $0-5$ years, based on a combination of developmental milestones and the Ten Questions Test developed for identifying severe disabilities in young children (Durkin et al. 1995). The outcome of the Ugandan pilot testing study was that the measures tested provided sufficiently accurate measures of disability for the purposes of eligibility for the social assistance grant. They correctly identified children and adults with severe difficulties. They did not, however, provide an accurate assessment of the nature of the disability. This requires a more detailed assessment tool.

The South African assessment and targeting for the disability grant has historically focused on a medical assessment by a medical doctor, resulting in disability being equated with illness. This has led to a situation where people feel they have a right to the disability grant because they have a chronic illness such as diabetes, hypertension or HIV/AIDS, even if they do not have any functional limitations (Swartz and Schneider 2006; Schneider and Goudge 2007). This was one of a number of reasons for a large and unexpected increase in the number of people applying for and receiving the disability grant in the period 2002-04 (CASE 2005). The revised assessment process for the $\mathrm{DG}$ and $\mathrm{CDG}$ reduced the weighting given to the medical assessment and introduced a detailed assessment of functional status, thereby emphasising the functional difficulties associated with disability, and differentiating disability and chronic illness more effectively. 


\section{Conclusion and moving forward}

Social assistance grants are about social protection and ensuring a sustainable livelihood and are, thus, a key intervention for disability. They ensure that members of a 'disabled' household are able to stay alive and attain some, albeit limited, level of control over their lives. The mainstreaming of disability within such programmes encompasses a recognition of the importance of disability as a vulnerability factor, and ensures that it is accurately assessed, targeted and monitored. The experiences of the three African countries discussed in this article suggest that this recognition is starting but that accurate assessment, targeting and monitoring requires more attention, such as developing standard measurement tools and formal collection of information on disability.

Targeting of disability should become explicit in all social protection and social assistance programmes, although the nature of the targeting will vary. Disability can be targeted as one of a range of factors to assess in relation to a household in programmes that target critical poverty (such as in Zambia and Uganda) or for a specific disability benefit (such as in South Africa).

\section{Notes}

1 The terms 'social cash transfers' (Zambia), 'social assistance' (Uganda) and 'social grants' (South Africa) are used interchangeably in this article.

2 A health condition can be a chronic, progressive or acute illness (mental or physical); an impairment (e.g. amputation, disfigurement); a disorder (e.g. Down's syndrome, autism); or a trauma (e.g. spinal cord injury, head injury). A health condition is not synonymous with being ill. Many health conditions (e.g. blindness, deafness, deformities), require little medical intervention, but rather require a range of other services that are accessible.

\section{References}

Braithwaite, J. and Mont, D. (2008) Disability and Poverty: A Survey of World Bank Poverty Assessments and Implications, Social Protection Discussion Paper 0805, Washington DC: World Bank, http://siteresources.worldbank.org/ DISABILITY/Resources/280658-1172608138489/ WBPovertyAssessments.pdf (accessed 4 July 2011)
The assessment of disability will vary from simple tools that serve to identify the presence or absence of disability (such as that proposed for SAGE in Uganda) through to complex assessment of the nature of the disability (as has been developed in South Africa).

Not all people with disabilities require a social assistance grant but they - including those who are social assistance beneficiaries - do require assistance in other ways, such as accessible services, assistance with extra costs associated with being disabled, carer allowances, and so on. However, disability being an important vulnerability factor will guarantee that many households targeted for a social assistance grant will have a member who is disabled.

Providing a social cash transfer is a necessary but not sufficient intervention strategy for ensuring that people with disabilities realise their rights and potential as human beings. The growing inclusion of disability in social assistance programmes in the African context is encouraging, but needs to be expanded to also creating inclusive services within comprehensive social protection policies and programmes.

3 The authors are grateful to Stephen Barrett of the SAGE programme (Social Protection Secretariat, Ministry of Gender, Labour and Social Development, Uganda) for allowing this information to be used.

4 See: http://cdc.gov/nchs/washington_group.htm (accessed 11 August 2011).

5 The problem with younger children is that difficulties in walking, communicating, etc. are often reported by parents when these are due to normal child development rather than to disability.

CASE (2005) 'Investigation into the Increase in the Uptake of Disability and Care Dependency Grants since December 2001', unpublished report for the National Treasury and the Department of Social Development, Johannesburg: Community Agency for Social Enquiry

de Koker, G.; de Waal, L. and Vorster, J. (2006) A Profile of Social Security Beneficiaries in South 
Africa, report for the Department of Social Development, Vol 1, Stellenbosch: Datadesk Durkin, M.S.; Wang, W.; Shrout, P.E.; Zaman, S.S.; Hasan, Z.M.; Desap, P. and Davidson, L.L. (1995) 'Evaluating a Ten Questions Screen for Childhood Disability: Reliability and Internal Structure in Different Cultures', Clinical Epidemiology 48.5: 657-66

Elwan, A. (1999) Poverty and Disability: A Survey of the Literature, Social Protection Discussion Paper 9932, Washington DC: World Bank, http://siteresources.worldbank.org/ DISABILITY/Resources/280658-1 172608138489/ PovertyDisabElwan.pdf (accessed 4 July 2011)

Goudge, J.; Russell, S. and Gilson, L. (2009a) 'Illness-related Impoverishment in Rural South Africa: Why does Social Protection Work for Some Households but not Others?', Journal of International Development 21.2: 231-51

Goudge, J.; Gilson, L.; Russell, S.; Gumede, T. and Mills, A. (2009b) 'Affordability, Availability and Acceptability Barriers to Health Care for the Chronically Ill: Longitudinal Case Studies from South Africa', BMC Health Services Research 9.75, doi:10.1186/1472-6963-9-75. Accessed 6 September 2011 at www.biomedcentral.com/ 1472-6963/9/75

Lwanga-Ntale, C. (2003) 'Chronic Poverty and Disability in Uganda', paper presented at the International Conference, Staying Poor: Chronic Poverty and Development Policy, University of Manchester, 7-9 April

Marriott, A. and Gooding, K. (2007) Social Assistance and Disability in Developing Countries, Sightsavers, www.undp-povertycentre.org/ publications/cct/Social_Assistance_Disability_ Gooding_Marriott.pdf (accessed 4 July 2011)

MCDSS and GTZ (2007) 'Social Safety Net Project - Final Evaluation Report, Kalomo Social Cash Transfer Scheme', unpublished report, Lusaka: Ministry of Community Development and Social Services (MCDSS) and Deutsche Gesellschaft für Technische Zusammenarbeit (GTZ)

Schneider, M. (2009) 'The Difference a Word Makes: Responding to Questions on "Disability" and "Difficulty" in South Africa', Disability and Rehabilitation 31.1: 42-50
Schneider, M. and Goudge, J. (2007) 'Developing a Policy Response to Provide Social Security Benefits to People with Chronic Diseases', unpublished report submitted to Department of Social Development, Pretoria: Human Sciences Research Council

Schneider, M.; Dasappa, P.; Khan, N. and Khan, A. (2009) 'Measuring Disability in Censuses: The Case of South Africa', ALTER: European Journal of Disability Research 3: 245-65

Schneider, M.; Waliuya, W.; Munsanje, J. and Simate, S. (2011) 'The Role of Social Cash Transfers for Persons with Disabilities and their Households in Kalomo and Monze, Zambia', unpublished report, Lusaka: Sightsavers International

Schubert, B. and Goldberg, J. (2004) The Pilot Social Cash Transfer Scheme: Kalomo DistrictZambia, www.sed.manchester.ac.uk/ research/events/conferences/documents/ Social\%20Protection\%20Papers/Schubert.pdf (accessed 24 January 2011)

Swartz, L. and Schneider, M. (2006) 'Tough

Choices: The Social Model of Disability, Social Security and the Challenges for

Implementation in South Africa', in

B. Watermeyer, L. Swartz, T. Lorenzo, M. Schneider and M. Priestley (eds), Disability and Social Change: A South African Agenda, Cape Town: HSRC Press

Tembo, G. and Freeland, N. (2007) 'Impact of Social Cash Transfers on Welfare, Investment and Education in Zambia', unpublished report for the Ministry of Community Development and Social Services, Lusaka: Palm Associates and London: Masdar International Consultants

United Nations (2006) Convention on the Rights of Persons with Disabilities, www.un.org/ disabilities/convention/conventionfull.shtml (accessed 4 July 2011)

Yeo, R. and Moore, K. (2003) 'Including Disabled People in Poverty Reduction Work: Nothing About Us, Without Us', World Development 31.3: $571-90$ 